\title{
The Role of Lipids in Hepatocellular Carcinoma
}

\author{
C. Nelson Hayes • Peiyi Zhang • Kazuaki Chayama \\ Department of Gastroenterology and Metabolism, Graduate School of Biomedical \& Health \\ Sciences, Applied Life Sciences, Institute of Biomedical \& Health Sciences, Hiroshima \\ University, Minami-ku, Hiroshima, Japan
}

Author for correspondence: C. Nelson Hayes, Department of Gastroenterology and Metabolism, Graduate School of Biomedical \& Health Sciences, Applied Life Sciences, Institute of Biomedical \& Health Sciences, Hiroshima University, 1-2-3 Kasumi, Minami-ku, Hiroshima 734-8551, Japan, Email: nelsonhayes@hiroshima-u.ac.jp Doi: http://dx.doi.org/10.15586/hepatocellularcarcinoma.2019.ch5

\begin{abstract}
Hepatocellular carcinoma is the fastest growing cause of cancerrelated mortality worldwide, with few treatment options and a 70\% recurrence rate. This trend is driven largely by the recent surge in incidence of metabolic syndrome, non-alcoholic fatty liver disease, and non-alcoholic steatohepatitis. Given the central role of the liver in lipid homeostasis, altered hepatic lipid metabolism has been identified as a contributing factor to hepatocellular carcinoma. Neoplastic cells are highly dependent on lipid metabolism as a source of energy and to support rapid cell division, and fatty acid derivatives play key roles in cell signaling. Aberrant expression of liver fatty acid-binding protein and changes in the ratio of saturated to unsaturated triacylglycerols have been shown to be associated with disease severity and subtype. This chapter focuses on metabolic reprogramming and dysregulation of lipid metabolism as hallmarks of hepatocellular carcinoma.
\end{abstract}

Keywords: carcinogenesis; fatty acid metabolism; lipidomics; lipid metabolic reprogramming; non-alcoholic steatohepatitis

In: Hepatocellular Carcinoma. Janina E.E. Tirnitz-Parker (Editor), Codon Publications, Brisbane, Australia. ISBN: 978-0-9944381-8-8. 2019; Doi: http://dx.doi.org/10.15586/ hepatocellularcarcinoma.2019

Copyright: The Authors.

License: This open access article is licensed under Creative Commons Attribution 4.0 International (CC BY 4.0). https://creativecommons.org/licenses/by-nc/4.0/ 


\section{INTRODUCTION}

Hepatocellular carcinoma (HCC) is the fastest growing cause of cancer-related mortality, with 840,000 new cases per year worldwide, nearly half of which are in China alone, due in part to the high (5.4\%) incidence of chronic hepatitis B virus (HBV) infection (1-3). The incidence of HCC in the United States has tripled over the last four decades, resulting in more than 30,000 new cases and 20,000 deaths per year $(1,4,5)$. HCC accounts for $75-85 \%$ of cases of primary liver cancer and is the sixth most common cause of cancer and the fourth most common cause of cancer-related death (3). A number of approaches have been developed to treat HCC, including liver resection, ablation, and transplantation. However, the disease is often asymptomatic at early stages and defies early detection. While the short-term prognosis for HCC has improved, the long-term prognosis remains poor, with a 5-year survival rate of $17 \%$ (6-8). Surgical resection provides the best chance for recovery, but the cancer is often detected too late for the treatment to be effective, and only about 15\% of patients are eligible (9). Even in the case of successful resection, the 5-year rate of HCC recurrence remains about $70 \%$ (10).

HCC is a complex disease with a number of known or suspected etiologies, including hepatitis B or C virus infection; non-alcoholic steatohepatitis (NASH); hemochromatosis; alcohol abuse; primary biliary cirrhosis; $\alpha-1$ antitrypsin deficiency; Wilson's disease; and carcinogens such as aflatoxin $\mathrm{B}_{1}$, thorotrast, polyvinyl chloride, and carbon tetrachloride $(11,12)$. However, inflammation associated with viral hepatitis and fatty liver disease is thought to be a common cross-etiological factor that drives the development of over 90\% of liver tumors (13). HBV accounts for $85 \%$ of HCC cases in endemic regions such as Southeast Asia and sub-Saharan Africa, whereas HCV is the leading risk factor for HCC in Europe and North America. While HBV and HCV have traditionally driven the majority of HCC cases, the proportion of non-viral HCC cases, especially due to NASH, is expected to increase exponentially, and the overall number of HCC cases is expected to skyrocket over the next decade due to increasing incidence of obesity and diabetes (14). Estes et al. projected that by 2030, the number of NAFLD cases in the United States will increase by $21 \%$, NASH cases by $63 \%$, and HCC cases by $137 \%$ (14).

The incidence of fatty liver-associated HCC is increasing in many western countries due to the alarming increase in the number of adults and children with obesity, diabetes, and metabolic syndrome (15). Lipid metabolism is among the liver's most critical functions. Along with proteins, carbohydrates, and nucleic acids, lipids represent one of the four main classes of biomolecules. Starvation depletes fat reserves and causes muscle wasting, whereas excessive caloric intake accompanied by lack of physical activity can lead to obesity, in which fat accumulates in the liver and adipose tissue, disrupting lipid homeostasis and promoting insulin resistance. Altered lipid metabolism is thought to induce inflammation and promote fibrosis (16). Defined as having a body mass index (BMI) greater than $30 \mathrm{~kg} / \mathrm{m}^{2}$, obesity is one of the greatest public health challenges of this century, affecting 700 million people worldwide (17). Now classified as a disease in its own right, obesity is a leading preventable cause of death and is associated with increased risk of diabetes, cardiovascular disease, depression, and several types of cancer, including esophageal adenocarcinoma, leukemia, non-Hodgkin's 


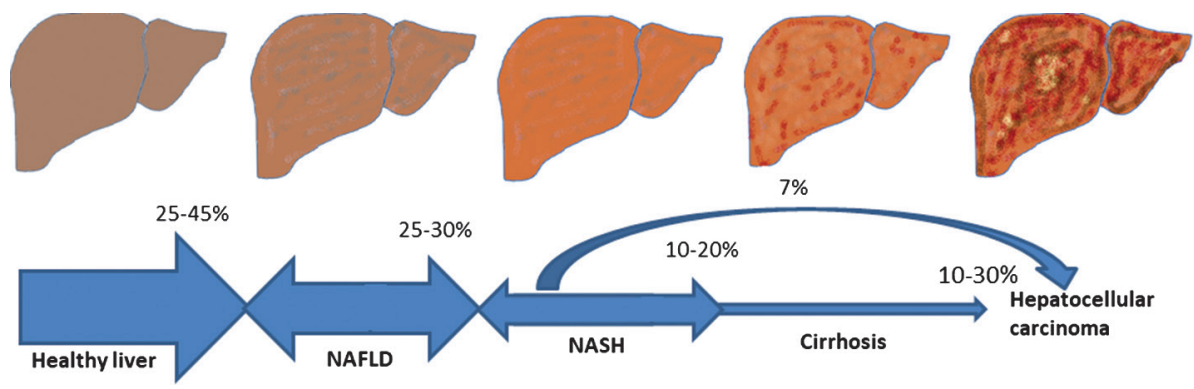

Figure 1 Potential routes of progression from fatty liver to hepatocellular carcinoma. Most steps are at least partially reversible with lifestyle changes, but a fraction of patients at each stage progresses to more severe liver inflammation and fibrosis until loss of hepatic function becomes mostly permanent. In some patients, HCC can develop on a more rapid course without cirrhosis.

lymphoma, multiple myeloma, malignant melanoma, and endometrial, colorectal, breast, prostate, thyroid, and renal cancers (18). Lipids play an intriguing role in the development of HCC, and factors associated with lipid and energy dysregulation, such as obesity (19), diabetes (20), and hepatic steatosis, are risk factors for HCC (21). Although the different viral, genetic, chemical, and metabolic etiologies of HCC vary with respect to early events leading to hepatocarcinogenesis, they increasingly converge on a set of shared biochemical pathways, of which lipid metabolism is a central player. For example, HBV infection, alcoholic liver disease, and NASH lead to increased lipogenesis and reduction of lysophosphatidylcholine $(22,23)$.

The pathophysiology of metabolic syndrome is complex and involves multiple organ systems, but in the liver the presence of excess fat promotes inflammation and can lead to cycles of liver cell injury and repair. Damage to the liver is often progressive and can result in fibrosis and eventually cirrhosis, but the process is often partially reversible at the early stages with changes in diet and lifestyle (Figure 1).

\section{NAFLD, CIRRHOSIS, AND HCC}

While the long-term progression from NAFLD to NASH to cirrhosis to HCC over a period of decades is frequently observed, there are exceptions. Being overweight increases the risk of HCC by $17 \%$, and obesity increases the risk by $89 \%$ (24). In patients with chronic HCV or HBV infection, the presence of NAFLD has been shown to increase the risk of oncogenesis in a synergistic manner (25), suggesting that lipid dysregulation is an independent risk factor for HCC.

NAFLD is on track to become the leading cause of non-cirrhotic HCC, in which liver cancer develops independently of cirrhosis (26-29) and might contribute to cryptogenic cirrhosis, in which the otherwise non-symptomatic cirrhosis is discovered incidentally $(30,31)$. The mechanism underlying cryptogenic HCC is unclear but may involve progression from NAFLD-based steatosis to lipid catabolism such that the underlying steatosis is no longer observable $(32,33)$. 
Some aspects of lipid dysregulation, such as attenuated lysophosphatidylcholine levels, have been found to be common in patients with NASH and cirrhosis (34), whereas levels of the non-essential amino acids such as valine and isoleucine were elevated in patients with cirrhosis $(35,36)$. Aside from its direct risks, cirrhosis is also the primary risk factor for HCC, and more than $90 \%$ of patients with HCC have cirrhosis (37). In a study of 34,932 patients with cirrhosis, 1,960 patients developed HCC (5.6\%) within 1.3 years (37). Currently, NASH-related cirrhosis accounts for about $10 \%$ of liver transplantations (38).

\section{HBV AND HCC}

Several studies have reported changes in lipid metabolism associated with HBV infection and liver regeneration. Park et al. reported significant changes in phosphatidylcholine composition in HBV-infected mouse livers and found that expression of choline-phosphate cytidylyltransferase A (PCYT1A) was significantly delayed (39). Using an HBx transgenic mouse model, Teng et al. tracked changes in lipid profiles during HBV-induced HCC and observed a biphasic peak in triglyceride, cholesterol, and fatty acid levels in serum and liver tissue (40). The first peak was associated with non-specific pro-inflammatory responses to oxidative stress in mouse hepatocytes. Lipid profiles then transiently resolved at 6 months before peaking again at 12 months, representing a terminal metabolic shift and formation of fatty nodules. The peaks were associated with the upregulation of the following five lipid metabolism-related genes, which were subsequently validated in human HBV-related HCC tumors: arachidonate 5-lipoxygenase, lipoprotein lipase, fatty acid-binding protein (FABP) 4, 1-acylglycerol-3-phosphate O-acyltransferase 9, and apolipoprotein A-IV (40). These results suggest that HBV-mediated perturbation of lipid metabolism plays a role in the mechanism of hepatocarcinogenesis.

\section{DE NOVO LIPOGENESIS IN HCC}

Given the role of lipids as structural, signaling, and energy storage molecules, there are a number of ways that lipid dysregulation could contribute to hepatocarcinogenesis. Increased de novo lipogenesis and enforced glycolysis appear to be hallmarks of liver cancer (41). One reason for this is the severe metabolic stress experienced within the poorly vascularized tumor core during rapid proliferation causing a nutrient-poor, hypoxic microenvironment on the brink of necrosis or apoptosis. Fatty acid oxidation can continue to provide energy required for cellular metabolism after glycogen has been depleted and in the absence of glucose from the blood. Therefore, glycolysis is elevated, and lipid catabolism is strongly and characteristically upregulated in HCC and other cancers as a means of cell survival. In rapidly proliferating tumor cells, elevated lipid catabolism helps to satisfy the high energy demands of the cells via acetyl$\mathrm{CoA}, \mathrm{NADH}$, and FADH and supplies glycerophospholipids for cell membrane formation (42). 


\section{LIPID METABOLIC REPROGRAMMING}

Although not fully understood and not as well studied as changes in glucose or glutamine metabolism, lipid metabolic reprogramming appears to be an effective strategy to sustain cancer stem cells in a hypoxic environment $(43,44)$. Tumor cells harboring beneficial metabolic changes, including those that produce prooncogenic metabolic intermediates, may undergo clonal selection (45). For example, the Warburg effect is a well-known adaptive strategy in which tumor cells forsake normal oxidative phosphorylation in exchange for less-efficient aerobic glycolysis, even in the presence of oxygen (46). Similarly, glutaminolysis helps to sustain the Krebs cycle via increased production of citrate and $\alpha$-ketoglutarate through elevated glutamine metabolism (47). Changes in fatty acid metabolism through metabolic reprogramming have also been found to play an important role in facilitating carcinogenesis (48). Generally, cells import fatty acids and other lipids from the blood, but HCC tumors upregulate genes involved in fatty acid biosynthesis, including SREBP-1-regulated genes such as ATP citrate lyase (ACLY), acetyl-CoA carboxylase (ACC), FAS, SCD-1, and GPAT, in order to generate fatty acids de novo $(48,49)$. A number of key enzymes, including ACLY, ACC, and fatty acid synthase (FASN), catalyze biosynthesis of fatty acids from citrate and acetyl-CoA. ACC catalyzes a key initial step in fatty acid biosynthesis, the conversion of acetyl-CoA to malonyl-CoA (50), and helps to sustain HCC tumors experiencing metabolic stress (51). As a rate-limiting enzyme in lipogenesis, elevated expression of ACC $\alpha$ has been reported to be an independent predictor associated with poor HCC prognosis (51). Similarly, FASN is a multifunctional enzyme that catalyzes the synthesis of long-chain saturated fatty acids during one of the final stages of fatty acid biosynthesis. FASN is over expressed in HCC as well as in many other types of cancer (52), and genetic ablation and drug targeting studies of FASN have revealed suppressed development of HCC $(41,53,54)$. Interestingly, aspirin has been shown to suppress abnormal lipid metabolism in hepatoma cells via NF-kB targeting by downregulating the expression of acyl-CoA synthetase long-chain family member 1 (ACSL1), which converts free fatty acids into fatty acyl-CoA esters, an early step in fatty acid degradation and important for lipid biosynthesis (55).

To exploit fatty acids as an efficient source of stored energy, $\beta$-oxidation has also been shown to be upregulated in HCC and other cancers $(49,56,57)$. In particular, 2-oxoglutarate is upregulated in HCC, and the levels of pyruvate and lactic acid are elevated, whereas carnitine esters, citrate, glycerol-3-phosphate, and free fatty acid levels are reduced $(36,58-61)$. This lipid-rich state is also associated with obesity, as obese patients not only take in more dietary fatty acids than non-obese patients but also hydrolyze more stored fats from adipose tissue. As a result, the liver is exposed to very high fatty acid levels. The liver adjusts to this stress through adaptive metabolic changes (metabolic reprogramming), such as a shift to aerobic glycolysis and increased glutamine synthesis to provide $\alpha$-ketoglutarate and citrate for the citric acid cycle, which collectively increase the risk of HCC (44). Obesity-mediated insulin resistance also promotes hyperinsulinemia, and oxidative and endoplasmic reticulum stress and changes in gut microbiota promote release of pro-inflammatory cytokines (62-68). The association between obesity and HCC suggests that 
use of statins to treat obesity by inhibiting hepatic cholesterol biosynthesis and metformin to treat insulin resistance might offer some protection against HCC (odds ratios 0.74 and 0.38 , respectively) $(69,70)$. FABPs, which regulate intracellular transport of fatty acids, are upregulated in a number of different cancers, including cancers of the bladder, breast, liver, lung, and prostate, and serve as biomarkers for cancer risk and aggressiveness (71). In a study of lipid-related HCC in a mouse model, Chiyonobu et al. showed that FABP4 was strongly upregulated in activated hepatic stellate cells (HSCs) resident within murine HCC tumors as well as in human metabolic-related HCC tumors but not in viral or alcohol-related HCCs, suggesting a mechanistic role of HSCs in NASH-related HCC (72).

\section{LIPIDOMICS}

Although a number of studies have examined changes in gene expression during HCC (73), fully understanding diseases as complex as NASH and HCC requires deep understanding of the internal state of individual cells. Single-cell transcriptomics is now possible; however, HCC tumor heterogeneity remains a challenge. A snapshot of the internal state can be partially reconstructed by assembling multiple complementary types of omics data. Lipidomics, first introduced in 2003 , is the branch of metabolomics charged with characterizing the diversity of fatty acids and other lipid products within a cell, tissue, organ, or biofluid. Another goal of lipidomics is to uncover the enzymatic mechanisms and turnover kinetics responsible for changes in lipid metabolism (74). The lipidome is complex, diverse, and dynamic, representing tens to hundreds of thousands of molecular species in a constant state of flux (74). The following is an overview of how lipidomics can help elucidate the molecular mechanisms that contribute to HCC. The common lipidomics methods and selected lipidomics studies pertinent to HCC are summarized in Tables 1 and 2, respectively.

Several metabolomics and lipidomics studies involving HCC or NASH have been performed (Table 2). Puri et al. reported elevated levels of saturated and monounsaturated fatty acids (especially palmitoleic acid and oleic acid) and reduced levels of polyunsaturated fatty acids (e.g., linoleic acid) in patients with NAFLD or NASH compared to healthy controls (90). Patterson et al. compared plasma samples from HCC patients, healthy controls, and patients with cirrhosis or acute myeloid leukemia using ultra-performance liquid chromatography electrospray ionization-quadrupole mass spectrometry (UPLC-ESI-QTOFMS) and ultra-performance liquid chromatography-electrospray ionization-triple quadrupole mass spectrometry (UPLC-ESI-TQMS) (91). They reported that glycodeoxycholate, deoxycholate 3-sulfate, bilirubin, biliverdin, and several fetal bile acids were elevated in the plasma of patients with HCC, whereas lysophosphocholine levels were reduced. Notably, they found that two very long chain fatty acids (VLCFAs), lignoceric acid and nervonic acid, were largely undetectable in plasma from HCC patients compared to patients with cirrhosis. Due to their extended length ( $\geq 22$ carbons), VLCFAs are synthesized through a multistep elongase-dependent pathway in the endoplasmic reticulum and must be metabolized in peroxisomes (92). 


\section{TABLE 1 Common lipidomics methods and selected lipidomics studies involving HCC}

\begin{tabular}{llc} 
Method & Description & $\begin{array}{c}\text { HCC lipidomics } \\
\text { studies }\end{array}$ \\
\hline GC & Gas chromatography & $(75)$ \\
UPLC-MS & Ultra-high performance liquid chromatography mass & $(76)$ \\
spectrometry & $(77)$ \\
MALDI-MS & Matrix-assisted laser desorption/ionization mass spectrometry & $(78)$ \\
ESI-MS & Electrospray ionization tandem mass spectrometry & $(79)$ \\
IMS & Imaging mass spectrometry & $(80)$ \\
LC-MS & Liquid chromatography mass spectrometry & $(60,81-83)$ \\
Shotgun lipidomics & Electrospray ionization mass spectrometry & $(82)$ \\
RPLC-MS & Reversed-phase liquid chromatography mass spectrometry & $(84)$ \\
LC/IT-TOF MS & Liquid chromatography/ion trap time-of-flight mass & $(85)$ \\
HPLC-MS & spectrometry & $(76,86)$ \\
DESI-MSI & High-performance liquid chromatography mass spectrometry \\
LC-ESI-MS & Desorption electrospray ionization mass spectrometry imaging & $(87)$ \\
UPLC-ESI-QTOF & Liquid chromatography electrospray ionization mass & Spltra-high performance liquid chromatography-electronic \\
MS & $\quad$ spray ionization-QTOF mass spectrometry & $(88)$ \\
MALDI-FTICR MS & Matrix-assisted laser desorption ionization-Fourier transform & ion cyclotron resonance mass spectrometry \\
GC-MS & Gas chromatography mass spectrometry & $(89)$ \\
& &
\end{tabular}

Lignoceric and nervonic acid, in particular, are involved in the maintenance of myelin, but VLCFAs are known to perform a range of functions, including skin barrier formation, sperm maturation, retinal functions, and liver homeostasis (92). VLCFAs also serve as precursors of inflammation-resolving lipid mediators, with potential roles in HCC formation (92). In a large case-control study comparing matched blood samples from patients before and after HCC diagnosis relative to healthy controls, Fages et al. identified a set of 16 metabolites involved in lipid and amino acid metabolism and ammonium detoxification that served as predictive biomarkers that differed between pre-diagnostic HCC patients and healthy controls, reflecting a characteristically altered metabolic state prior to HCC development (93). Two studies in China also reported panels of serum amino acid and fatty acid biomarkers able to predict HCC with area under the curve (AUC) greater than $0.96(61,94)$. Lin et al. recently showed that a decrease in palmitic acyl-based glycerophospholipids, a key component of the cell membrane, was associated with metastatic HCC (86). 


\section{TABLE 2 Selected lipidomics studies}

\section{Study}

Muir et al. (75)

Weylandt et al. (76)

Passos-Castilho et al. (77)

Passos-Castilho et al. (78)

Krautbauer et al. (79)

Morita et al. (80)

Lu et al. (81)

Zhou et al. (60)

Lu et al. (83)

Chen et al. (85)

Lin et al. (86)

Li et al. (89)

\section{Description}

The authors reported an increased ratio of long chain n6-polyunsaturated fatty acids to n3-polyunsaturated fatty acids in NASH and HCC using a Pten-null mouse model.

Using a fat-1 transgenic mouse model, the authors showed that increased omega-3 polyunsaturated fatty acids suppress HCC tumorigenesis by reducing inflammation.

Serum ultra-high performance liquid chromatography mass spectrometry (UPLC-MS) lipid profiles discriminated patients with HBV-related HCC from patients with chronic HBV.

Matrix-assisted laser desorption/ionization mass spectrometry lipid profiles discriminated patients with HCV-related HCC from patients with chronic $\mathrm{HCV}$.

Ceramide levels were found to be notably reduced in HCC tissues.

Levels of phosphatidylcholine containing palmitoleic acid or oleic acid were found to be elevated in HCC using imaging mass spectrometry.

Lipid signatures varied between HCC and serum samples. Plasmalogens (36:4) and (40:6) are potential serum biomarkers for HCC.

Using liquid chromatography-mass spectrometry of serum samples, higher levels of long-chain acylcarnitines and lower levels of free carnitine and medium and short-chain acylcarnitines were detected in HCC.

Mass spectroscopic analysis of matched tissue and serum samples from patients with HCC was used to evaluate the usefulness of acetylcarnitine as a biomarker.

Ultra-fast LC/IT-TOF MS serum lipidomics was used to compare lipid profiles for patients with HBV, cirrhosis, and HCC. 75 out of 96 lipids were downregulated in patients with HCC compared to healthy patients.

Lipid profiling of HCC cells revealed anomalies affecting 93 different lipids. Reduced palmitic acyl glycerophosholipids were associated with greater metastatic activity.

The number of polyunsaturated triacylglycerols with $>2$ double bonds was found to be reduced based on lipid profiling using UPLC-ESI-QTOF MS and MALDI-FTICR MS.

\section{THERAPEUTIC ADVANCES TARGETING LIPID METABOLISM}

Despite a better understanding of lipid metabolism, drugs targeting key steps in lipogenesis in various types of cancer are still in the experimental stage (Table 3) $(95,96)$. Given the central regulatory role of SREBPs in lipid metabolism, SREBPs represent promising drug targets. SREBP-1 and SREBP-2 are upregulated in glioblastoma and prostate cancer, respectively, and SREBP ablation or blocking has 


\section{TABLE 3 Drugs targeting lipid metabolism in tumor cells}

\begin{tabular}{|c|c|c|c|c|c|}
\hline Year & Compound & Target & Tumor Type & Model & Ref. \\
\hline 2019 & Simvastatin & Lipid rafts & Human lung cancer & A549 cell & $(101)$ \\
\hline 2018 & $\begin{array}{l}\text { Paclitaxel and } \\
\text { vinblastine }\end{array}$ & $\begin{array}{r}\text { Microtubule } \\
\text { dynamics }\end{array}$ & Human osteosarcoma & U2OS cell & (102) \\
\hline 2017 & Betulin & SREBPS & Human liver cancer & $\begin{array}{l}\text { Diethylnitrosamine- } \\
\text { injected mice } \\
\text { model }\end{array}$ & (83) \\
\hline 2017 & Cetuximab & $\begin{array}{l}\text { Acetyl-CoA } \\
\text { carboxylase } \\
\text { (ACC) }\end{array}$ & $\begin{array}{l}\text { Head and neck } \\
\text { squamous cell } \\
\text { carcinoma } \\
\text { (HNSCC) }\end{array}$ & $\begin{array}{l}\text { HN5, FaDu, } \\
\text { Tu159, OSC19, } \\
\text { MDA1986, } \\
\text { UMSCC1, and } \\
\text { Tu167) }\end{array}$ & $(103)$ \\
\hline 2016 & $\begin{array}{l}\text { Nutlin-3 and } \\
\text { actinomycin D }\end{array}$ & $\begin{array}{l}\text { Ceramide synthase } 6 \\
\text { (CerS6) }\end{array}$ & Human lung cancer & A549 cell & $(104)$ \\
\hline 2015 & TVB-2640 & $\begin{array}{l}\text { Fatty acid synthase } \\
\text { (FASN) }\end{array}$ & - & Phase I & (105) \\
\hline 2014 & $\begin{array}{l}\text { Azoxymethane/ } \\
\text { dextran sodium } \\
\text { sulfate }\end{array}$ & $\begin{array}{l}\text { Sphingosine-1- } \\
\text { phosphate (SIP) } \\
\text { lyase (SPL) }\end{array}$ & $\begin{array}{c}\text { Colitis-associated } \\
\text { cancer (CAC) }\end{array}$ & CAC murine model & (106) \\
\hline 2012 & $\mathrm{C} 75$ & FASN & Prostate cancer (PC) & LNCaP cell & (107) \\
\hline 2010 & PX-866 & PI3K & Human glioblastoma & $\begin{array}{l}\text { U251, U87, } \\
\text { LN229, and } \\
\text { LN18 cells }\end{array}$ & $(108)$ \\
\hline 2010 & NDNSAs & Unknown & Human breast cancer & MCF-7 cell & (109) \\
\hline 2009 & LCL385 & $\begin{array}{l}\text { Acid ceramidase } \\
\text { (AC) }\end{array}$ & PC & PPC-1 cell & (110) \\
\hline 2009 & 15-dPGJ2 & PPARY & Colorectal cancer & $\begin{array}{l}\text { CT-26 s.c. tumor } \\
\text { model and an } \\
\text { HL- } 60 \text { xenograft } \\
\text { model }\end{array}$ & (111) \\
\hline
\end{tabular}

been shown to induce cancer cell death and suppression of tumor growth (95). However, development of drugs that directly target transcription factors is difficult, and efforts have instead focused on drugs such as betulin, fatostatin, xanthohumol, and PF-429242 that inhibit the translocation of SREBP to the Golgi apparatus (95). Li et al. examined whether inhibition of de novo lipid biosynthesis is protective against HCC by blocking SREBP cleavage-activating protein in hepatocytes using betulin in a diethylnitrosamine-induced HCC mouse model (97). They found that blocking or ablation of this key component of the SREBP pathway suppressed HCC. Drugs have also been developed targeting specific steps in lipid metabolism. The ACC inhibitor GS-0976 has been found to reduce the extent of liver steatosis and fibrosis in NASH patients $(98,99)$, and drug targeting 
of FASN has been shown to suppress HCC development $(41,53,54)$. Several existing drugs such as statins and metformin are thought to have a protective effect against HCC $(69,70)$. Statins, as lipid-lowering agents, have long been used for the treatment of heart disease. They have also been reported to have a protective effect against tumorigenesis. Some published evidence supports the use of statins in HCC prevention in patients with liver disease (100).

\section{CONCLUSION}

While much progress has been made in limiting viral and environmental causes of HCC, new cases of NASH-related HCC are currently increasing and are likely to continue to increase for the foreseeable future. Many cases of NASH-related HCC are preventable through changes in lifestyle, including exercise and reduced intake of fructose and high-fat foods, but such changes are difficult to maintain. Therefore, there is an important unmet need to develop biomarkers to monitor changes in hepatic lipid metabolism in NAFLD patients, so that it is possible to intervene as early as possible in patients with the highest risk of progressing to NASH and cirrhosis. Early detection of HCC offers the best chance of treatment, while few procedures significantly improve survival in the case of advanced HCC. It is essential to determine the key molecular events that trigger hepatocarcinogenesis in order to facilitate drug development to prevent or slow development of HCC. Lipidomics provides a valuable tool to assess the detailed metabolic changes that may lead to initiation of liver cancer.

Conflict of Interest: Kazuaki Chayama has received honoraria from Bristol-Myers Squibb and MSD K.K. and research funding from Dainippon Sumitomo Pharma and AbbVie. The other authors declare no potential conflicts of interest with respect to research, authorship, and/or publication of this article.

Copyright and Permission Statement: To the best of our knowledge, the materials included in this chapter do not violate copyright laws. All original sources have been appropriately acknowledged and/or referenced. Where relevant, appropriate permissions have been obtained from the original copyright holder(s).

\section{REFERENCES}

1. Nakayoshi T, Adachi H, Ohbu-Murayama K, Enomono M, Fukami A, Kumagai E, et al. Plasma heat shock protein 27 is increased in renal dysfunction and habitual smoking in a Japanese general population. J Cardiol. 2016;67(1):110-14. http://dx.doi.org/10.1016/j.jjcc.2015.04.005

2. World Health Organization: Globocan 2018 - China Factsheet. [cited 2019 Jul 10]. Available from: http://gco.iarc.fr/today/data/factsheets/populations/160-china-fact-sheets.pdf

3. Rawla P, Sunkara T, Muralidharan P, Raj JP. Update in global trends and aetiology of hepatocellular carcinoma. Contemp Oncol (Pozn). 2018;22(3):141-50. http://dx.doi.org/10.5114/wo.2018.78941

4. Altekruse SF, McGlynn KA, Reichman ME. Hepatocellular carcinoma incidence, mortality, and survival trends in the United States from 1975 to 2005. J Clin Oncol. 2009;27(9):1485-91. http://dx.doi. org/10.1200/JCO.2008.20.7753 
5. Siegel R, Ma J, Zou Z, Jemal A. Cancer statistics, 2014. CA Cancer J Clin. 2014;64(1):9-29. http:// dx.doi.org/10.3322/caac. 21208

6. Gluer AM, Cocco N, Laurence JM, Johnston ES, Hollands MJ, Pleass HC, et al. Systematic review of actual 10-year survival following resection for hepatocellular carcinoma. HPB (Oxford). 2012;14(5):285-90. http://dx.doi.org/10.1111/j.1477-2574.2012.00446.x

7. Shiina S, Tateishi R, Arano T, Uchino K, Enooku K, Nakagawa H, et al. Radiofrequency ablation for hepatocellular carcinoma: 10-year outcome and prognostic factors. Am J Gastroenterol. 2012;107(4):569-77; quiz 78. http://dx.doi.org/10.1038/ajg.2011.425

8. Zheng J, Kuk D, Gonen M, Balachandran VP, Kingham TP, Allen PJ, et al. Actual 10-year survivors after resection of hepatocellular carcinoma. Ann Surg Oncol. 2017;24(5):1358-66. http://dx.doi. org/10.1245/s10434-016-5713-2

9. Sherman M. Hepatocellular carcinoma: Epidemiology, risk factors, and screening. Semin Liver Dis. 2005;25(2):143-54. http://dx.doi.org/10.1055/s-2005-871194

10. El-Serag HB. Hepatocellular carcinoma. N Engl J Med. 2011;365(12):1118-27. http://dx.doi. org/10.1056/NEJMral001683

11. Jindal A, Thadi A, Shailubhai K. Hepatocellular carcinoma: Etiology and current and future drugs. J Clin Exp Hepatol. 2019;9(2):221-32. http://dx.doi.org/10.1016/j.jceh.2019.01.004

12. Friedman LS, Martin P. Handbook of liver disease. 4th. ed. Philadelphia, PA: Elsevier; 2018. xxvi, $547 \mathrm{p}$.

13. Nakagawa H, Maeda S. Inflammation- and stress-related signaling pathways in hepatocarcinogenesis. World J Gastroenterol. 2012;18(31):4071-81. http://dx.doi.org/10.3748/wjg.vl8.i31.4071

14. Estes C, Razavi H, Loomba R, Younossi Z, Sanyal AJ. Modeling the epidemic of nonalcoholic fatty liver disease demonstrates an exponential increase in burden of disease. Hepatology. 2018;67(1):123-33. http://dx.doi.org/10.1002/hep.29466

15. Younossi ZM. Non-alcoholic fatty liver disease - A global public health perspective. J Hepatol. 2019;70(3):531-44. http://dx.doi.org/10.1016/j.jhep.2018.10.033

16. Moustafa T, Fickert P, Magnes C, Guelly C, Thueringer A, Frank S, et al. Alterations in lipid metabolism mediate inflammation, fibrosis, and proliferation in a mouse model of chronic cholestatic liver injury. Gastroenterology. 2012;142(1):140-51 el2. http://dx.doi.org/10.1053/j.gastro.2011.09.051

17. Collaborators GBDO, Afshin A, Forouzanfar MH, Reitsma MB, Sur P, Estep K, et al. Health effects of overweight and obesity in 195 countries over 25 years. N Engl J Med. 2017;377(1):13-27. http:// dx.doi.org/10.1056/NEJMoal614362

18. De Pergola G, Silvestris F. Obesity as a major risk factor for cancer. J Obes. 2013;2013:291546. http:// dx.doi.org/10.1155/2013/291546

19. Calle EE, Rodriguez C, Walker-Thurmond K, Thun MJ. Overweight, obesity, and mortality from cancer in a prospectively studied cohort of U.S. adults. N Engl J Med. 2003;348(17):1625-38. http:// dx.doi.org/10.1056/NEJMoa021423

20. Mittal S, El-Serag HB. Epidemiology of hepatocellular carcinoma: Consider the population. J Clin Gastroenterol. 2013;47(Suppl):S2-6. http://dx.doi.org/10.1097/MCG.0b013e3182872f29

21. Pekow JR, Bhan AK, Zheng H, Chung RT. Hepatic steatosis is associated with increased frequency of hepatocellular carcinoma in patients with hepatitis C-related cirrhosis. Cancer. 2007;109(12):2490-6. http://dx.doi.org/10.1002/cncr.22701

22. Zivkovic AM, Bruce German J, Esfandiari F, Halsted CH. Quantitative lipid metabolomic changes in alcoholic micropigs with fatty liver disease. Alcohol Clin Exp Res. 2009;33(4):751-8. http://dx.doi. org/10.1111/j.1530-0277.2008.00892.x

23. Yin $\mathrm{P}$, Wan $\mathrm{D}$, Zhao C, Chen J, Zhao X, Wang W, et al. A metabonomic study of hepatitis B-induced liver cirrhosis and hepatocellular carcinoma by using RP-LC and HILIC coupled with mass spectrometry. Mol Biosyst. 2009;5(8):868-76. http://dx.doi.org/10.1039/b820224a

24. Larsson SC, Wolk A. Overweight, obesity and risk of liver cancer: A meta-analysis of cohort studies. Br J Cancer. 2007;97(7):1005-8. http://dx.doi.org/10.1038/sj.bjc.6603932

25. Chen CL, Yang HI, Yang WS, Liu CJ, Chen PJ, You SL, et al. Metabolic factors and risk of hepatocellular carcinoma by chronic hepatitis B/C infection: A follow-up study in Taiwan. Gastroenterology. 2008;135(1):111-21. http://dx.doi.org/10.1053/j.gastro.2008.03.073 
26. Marrero JA, Fontana RJ, Su GL, Conjeevaram HS, Emick DM, Lok AS. NAFLD may be a common underlying liver disease in patients with hepatocellular carcinoma in the United States. Hepatology. 2002;36(6):1349-54. http://dx.doi.org/10.1002/hep.1840360609

27. Pais R, Fartoux L, Goumard C, Scatton O, Wendum D, Rosmorduc O, et al. Temporal trends, clinical patterns and outcomes of NAFLD-related HCC in patients undergoing liver resection over a 20-year period. Aliment Pharmacol Ther. 2017;46(9):856-63. http://dx.doi.org/10.1111/apt.14261

28. Schutte K, Schulz C, Poranzke J, Antweiler K, Bornschein J, Bretschneider T, et al. Characterization and prognosis of patients with hepatocellular carcinoma (HCC) in the non-cirrhotic liver. BMC Gastroenterol. 2014;14:117. http://dx.doi.org/10.1186/1471-230X-14-117

29. Desai A, Sandhu S, Lai JP, Sandhu DS. Hepatocellular carcinoma in non-cirrhotic liver: A comprehensive review. World J Hepatol. 2019;11(1):1-18. http://dx.doi.org/10.4254/wjh.v11.il.1

30. Caldwell S. Cryptogenic cirrhosis: What are we missing? Curr Gastroenterol Rep. 2010;12(1):40-8. http://dx.doi.org/10.1007/s11894-009-0082-7

31. El-Serag HB, Rudolph KL. Hepatocellular carcinoma: Epidemiology and molecular carcinogenesis. Gastroenterology. 2007;132(7):2557-76. http://dx.doi.org/10.1053/j.gastro.2007.04.061

32. Caldwell SH, Oelsner DH, Iezzoni JC, Hespenheide EE, Battle EH, Driscoll CJ. Cryptogenic cirrhosis: Clinical characterization and risk factors for underlying disease. Hepatology. 1999;29(3):664-9. http://dx.doi.org/10.1002/hep.510290347

33. Lee SS, Jeong SH, Byoun YS, Chung SM, Seong MH, Sohn HR, et al. Clinical features and outcome of cryptogenic hepatocellular carcinoma compared to those of viral and alcoholic hepatocellular carcinoma. BMC Cancer. 2013;13:335. http://dx.doi.org/10.1186/1471-2407-13-335

34. Lian JS, Liu W, Hao SR, Guo YZ, Huang HJ, Chen DY, et al. A serum metabonomic study on the difference between alcohol- and HBV-induced liver cirrhosis by ultraperformance liquid chromatography coupled to mass spectrometry plus quadrupole time-of-flight mass spectrometry. Chin Med J (Engl). 2011;124(9):1367-73.

35. Waldhier MC, Almstetter MF, Nurnberger N, Gruber MA, Dettmer K, Oefner PJ. Improved enantiomer resolution and quantification of free D-amino acids in serum and urine by comprehensive two-dimensional gas chromatography-time-of-flight mass spectrometry. J Chromatogr A. 2011;1218(28):4537-44. http://dx.doi.org/10.1016/j.chroma.2011.05.039

36. Gao H, Lu Q, Liu X, Cong H, Zhao L, Wang H, et al. Application of 1H NMR-based metabonomics in the study of metabolic profiling of human hepatocellular carcinoma and liver cirrhosis. Cancer Sci. 2009;100(4):782-5. http://dx.doi.org/10.1111/j.1349-7006.2009.01086.x

37. Flemming JA, Yang JD, Vittinghoff E, Kim WR, Terrault NA. Risk prediction of hepatocellular carcinoma in patients with cirrhosis: The ADRESS-HCC risk model. Cancer. 2014;120(22):3485-93. http://dx.doi.org/10.1002/cncr.28832

38. Browning JD, Szczepaniak LS, Dobbins R, Nuremberg P, Horton JD, Cohen JC, et al. Prevalence of hepatic steatosis in an urban population in the United States: Impact of ethnicity. Hepatology. 2004;40(6):1387-95. http://dx.doi.org/10.1002/hep.20466

39. Park ES, Lee JH, Hong JH, Park YK, Lee JW, Lee WJ, et al. Phosphatidylcholine alteration identified using MALDI imaging MS in HBV-infected mouse livers and virus-mediated regeneration defects. PLoS One. 2014;9(8):e103955. http://dx.doi.org/10.1371/journal.pone.0103955

40. Teng CF, Hsieh WC, Yang CW, Su HM, Tsai TF, Sung WC, et al. A biphasic response pattern of lipid metabolomics in the stage progression of hepatitis B virus $\mathrm{X}$ tumorigenesis. Mol Carcinog. 2016;55(1):105-14. http://dx.doi.org/10.1002/mc.22266

41. Calvisi DF, Wang C, Ho C, Ladu S, Lee SA, Mattu S, et al. Increased lipogenesis, induced by AKT-mTORCl-RPS6 signaling, promotes development of human hepatocellular carcinoma. Gastroenterology. 2011;140(3):1071-83. http://dx.doi.org/10.1053/j.gastro.2010.12.006

42. Santos CR, Schulze A. Lipid metabolism in cancer. FEBS J. 2012;279(15):2610-23. http://dx.doi. org/10.1111/j.1742-4658.2012.08644.x

43. Fujiwara N, Nakagawa H, Enooku K, Kudo Y, Hayata Y, Nakatsuka T, et al. CPT2 downregulation adapts HCC to lipid-rich environment and promotes carcinogenesis via acylcarnitine accumulation in obesity. Gut. 2018;67(8):1493-504. http://dx.doi.org/10.1136/gutjnl-2017-315193

44. Nakagawa H, Hayata Y, Kawamura S, Yamada T, Fujiwara N, Koike K. Lipid metabolic reprogramming in hepatocellular carcinoma. Cancers (Basel). 2018;10(11). http://dx.doi.org/10.3390/cancers10110447 
45. Ward PS, Thompson CB. Metabolic reprogramming: A cancer hallmark even warburg did not anticipate. Cancer Cell. 2012;21(3):297-308. http://dx.doi.org/10.1016/j.ccr.2012.02.014

46. Vander Heiden MG, Cantley LC, Thompson CB. Understanding the Warburg effect: The metabolic requirements of cell proliferation. Science. 2009;324(5930):1029-33. http://dx.doi.org/10.1126/ science. 1160809

47. Wise DR, Thompson CB. Glutamine addiction: A new therapeutic target in cancer. Trends Biochem Sci. 2010;35(8):427-33. http://dx.doi.org/10.1016/j.tibs.2010.05.003

48. Currie E, Schulze A, Zechner R, Walther TC, Farese RV, Jr. Cellular fatty acid metabolism and cancer. Cell Metab. 2013;18(2):153-61. http://dx.doi.org/10.1016/j.cmet.2013.05.017

49. Bjornson E, Mukhopadhyay B, Asplund A, Pristovsek N, Cinar R, Romeo S, et al. Stratification of hepatocellular carcinoma patients based on acetate utilization. Cell Rep. 2015;13(9):2014-26. http:// dx.doi.org/10.1016/j.celrep.2015.10.045

50. Stryer L. Biochemistry. 4th ed. New York: W.H. Freeman; 1995. xxxiv, 1064 p.

51. Wang MD, Wu H, Fu GB, Zhang HL, Zhou X, Tang L, et al. Acetyl-coenzyme A carboxylase alpha promotion of glucose-mediated fatty acid synthesis enhances survival of hepatocellular carcinoma in mice and patients. Hepatology. 2016;63(4):1272-86. http://dx.doi.org/10.1002/hep.28415

52. Menendez JA, Lupu R. Fatty acid synthase and the lipogenic phenotype in cancer pathogenesis. Nat Rev Cancer. 2007;7(10):763-77. http://dx.doi.org/10.1038/nrc2222

53. Li L, Pilo GM, Li X, Cigliano A, Latte G, Che L, et al. Inactivation of fatty acid synthase impairs hepatocarcinogenesis driven by AKT in mice and humans. J Hepatol. 2016;64(2):333-41. http://dx.doi. org/10.1016/j.jhep.2015.10.004

54. Hao Q, Li T, Zhang X, Gao P, Qiao P, Li S, et al. Expression and roles of fatty acid synthase in hepatocellular carcinoma. Oncol Rep. 2014;32(6):2471-6. http://dx.doi.org/10.3892/or.2014.3484

55. Yang G, Wang Y, Feng J, Liu Y, Wang T, Zhao M, et al. Aspirin suppresses the abnormal lipid metabolism in liver cancer cells via disrupting an NFkappaB-ACSLl signaling. Biochem Biophys Res Commun. 2017;486(3):827-32. http://dx.doi.org/10.1016/j.bbrc.2017.03.139

56. Beloribi-Djefaflia S, Vasseur S, Guillaumond F. Lipid metabolic reprogramming in cancer cells. Oncogenesis. 2016;5:e189. http://dx.doi.org/10.1038/oncsis.2015.49

57. Zaugg K, Yao Y, Reilly PT, Kannan K, Kiarash R, Mason J, et al. Carnitine palmitoyltransferase 1C promotes cell survival and tumor growth under conditions of metabolic stress. Genes Dev. 2011;25(10):1041-51. http://dx.doi.org/10.110l/gad.1987211

58. Beyoglu D, Imbeaud S, Maurhofer O, Bioulac-Sage P, Zucman-Rossi J, Dufour JF, et al. Tissue metabolomics of hepatocellular carcinoma: Tumor energy metabolism and the role of transcriptomic classification. Hepatology. 2013;58(1):229-38. http://dx.doi.org/10.1002/hep.26350

59. Chen T, Xie G, Wang X, Fan J, Qiu Y, Zheng X, et al. Serum and urine metabolite profiling reveals potential biomarkers of human hepatocellular carcinoma. Mol Cell Proteomics. 2011;10(7):M110 004945. http://dx.doi.org/10.1074/mcp.M110.004945

60. Zhou L, Wang Q, Yin P, Xing W, Wu Z, Chen S, et al. Serum metabolomics reveals the deregulation of fatty acids metabolism in hepatocellular carcinoma and chronic liver diseases. Anal Bioanal Chem. 2012;403(1):203-13. http://dx. doi.org/10.1007/s00216-012-5782-4

61. Liu Y, Hong Z, Tan G, Dong X, Yang G, Zhao L, et al. NMR and LC/MS-based global metabolomics to identify serum biomarkers differentiating hepatocellular carcinoma from liver cirrhosis. Int J Cancer. 2014;135(3):658-68. http://dx.doi.org/10.1002/ijc.28706

62. Nakagawa H, Umemura A, Taniguchi K, Font-Burgada J, Dhar D, Ogata H, et al. ER stress cooperates with hypernutrition to trigger TNF-dependent spontaneous HCC development. Cancer Cell. 2014;26(3):331-43. http://dx.doi.org/10.1016/j.ccr.2014.07.001

63. Park EJ, Lee JH, Yu GY, He G, Ali SR, Holzer RG, et al. Dietary and genetic obesity promote liver inflammation and tumorigenesis by enhancing IL-6 and TNF expression. Cell. 2010;140(2):197-208. http://dx.doi.org/10.1016/j.cell.2009.12.052

64. Nakagawa H. How endoplasmic reticulum stress contributes to obesity-driven hepatic tumorigenesis. Hepat Oncol. 2015;2(3):209-11. http://dx.doi.org/10.2217/hep.15.11

65. Yoshimoto S, Loo TM, Atarashi K, Kanda H, Sato S, Oyadomari S, et al. Obesity-induced gut microbial metabolite promotes liver cancer through senescence secretome. Nature. 2013;499(7456):97-101. http://dx.doi.org/10.1038/nature12347 
66. Arano T, Nakagawa H, Tateishi R, Ikeda H, Uchino K, Enooku K, et al. Serum level of adiponectin and the risk of liver cancer development in chronic hepatitis C patients. Int J Cancer. 2011;129(9):2226-35. http://dx.doi.org/10.1002/ijc.25861

67. Shalapour S, Lin XJ, Bastian IN, Brain J, Burt AD, Aksenov AA, et al. Inflammation-induced IgA+ cells dismantle anti-liver cancer immunity. Nature. 2017;551(7680):340-5. http://dx.doi.org/10.1038/ nature 24302

68. Nakagawa H. Recent advances in mouse models of obesity- and nonalcoholic steatohepatitisassociated hepatocarcinogenesis. World J Hepatol. 2015;7(17):2110-18. http://dx.doi.org/10.4254/ wjh.v7.i17.2110

69. El-Serag HB, Johnson ML, Hachem C, Morgana RO. Statins are associated with a reduced risk of hepatocellular carcinoma in a large cohort of patients with diabetes. Gastroenterology. 2009;136(5):1601-8. http://dx.doi.org/10.1053/j.gastro.2009.01.053

70. Zhang ZJ, Zheng ZJ, Shi R, Su Q, Jiang Q, Kip KE. Metformin for liver cancer prevention in patients with type 2 diabetes: A systematic review and meta-analysis. J Clin Endocrinol Metab. 2012;97(7):2347-53. http://dx.doi.org/10.1210/jc.2012-1267

71. Amiri M, Yousefnia S, Seyed Forootan F, Peymani M, Ghaedi K, Nasr Esfahani MH. Diverse roles of fatty acid binding proteins (FABPs) in development and pathogenesis of cancers. Gene. 2018;676:171-83. http://dx.doi.org/10.1016/j.gene.2018.07.035

72. Chiyonobu N, Shimada S, Akiyama Y, Mogushi K, Itoh M, Akahoshi K, et al. Fatty acid binding protein 4 (FABP4) overexpression in intratumoral hepatic stellate cells within hepatocellular carcinoma with metabolic risk factors. Am J Pathol. 2018;188(5):1213-24. http://dx.doi.org/10.1016/j. ajpath.2018.01.012

73. Arzumanyan A, Reis HM, Feitelson MA. Pathogenic mechanisms in HBV- and HCV-associated hepatocellular carcinoma. Nat Rev Cancer. 2013;13(2):123-35. http://dx.doi.org/10.1038/nrc3449

74. Yang K, Han X. Lipidomics: Techniques, applications, and outcomes related to biomedical sciences. Trends Biochem Sci. 2016;41(11):954-69. http://dx.doi.org/10.1016/j.tibs.2016.08.010

75. Muir K, Hazim A, He Y, Peyressatre M, Kim DY, Song X, et al. Proteomic and lipidomic signatures of lipid metabolism in NASH-associated hepatocellular carcinoma. Cancer Res. 2013;73(15):4722-31. http://dx.doi.org/10.1158/0008-5472.CAN-12-3797

76. Weylandt KH, Krause LF, Gomolka B, Chiu CY, Bilal S, Nadolny A, et al. Suppressed liver tumorigenesis in fat-1 mice with elevated omega-3 fatty acids is associated with increased omega-3 derived lipid mediators and reduced TNF-alpha. Carcinogenesis. 2011;32(6):897-903. http://dx.doi.org/10.1093/ carcin/bgr049

77. Passos-Castilho AM, Carvalho VM, Cardozo KH, Kikuchi L, Chagas AL, Gomes-Gouvea MS, et al. Serum lipidomic profiling as a useful tool for screening potential biomarkers of hepatitis B-related hepatocellular carcinoma by ultraperformance liquid chromatography-mass spectrometry. BMC Cancer. 2015;15:985. http://dx.doi.org/10.1186/s12885-015-1995-1

78. Passos-Castilho AM, Lo Turco E, Ferraz ML, Matos C, Silva I, Parise E, et al. Plasma lipidomic fingerprinting to distinguish among hepatitis C-related hepatocellular carcinoma, liver cirrhosis, and chronic hepatitis C using MALDI-TOF mass spectrometry: A pilot study. J Gastrointestin Liver Dis. 2015;24(1):43-9. http://dx.doi.org/10.15403/jgld.2014.1121.pas

79. Krautbauer S, Meier EM, Rein-Fischboeck L, Pohl R, Weiss TS, Sigruener A, et al. Ceramide and polyunsaturated phospholipids are strongly reduced in human hepatocellular carcinoma. Biochim Biophys Acta. 2016;1861(11):1767-74. http://dx.doi.org/10.1016/j.bbalip.2016.08.014

80. Morita Y, Sakaguchi T, Ikegami K, Goto-Inoue N, Hayasaka T, Hang VT, et al. Lysophosphatidylcholine acyltransferase 1 altered phospholipid composition and regulated hepatoma progression. J Hepatol. 2013;59(2):292-9. http://dx.doi.org/10.1016/j.jhep.2013.02.030

81. Lu Y, Chen J, Huang C, Li N, Zou L, Chia SE, et al. Comparison of hepatic and serum lipid signatures in hepatocellular carcinoma patients leads to the discovery of diagnostic and prognostic biomarkers. Oncotarget. 2018;9(4):5032-43. http://dx.doi.org/10.18632/oncotarget.23494

82. Zhong H, Xiao M, Zarkovic K, Zhu M, Sa R, Lu J, et al. Mitochondrial control of apoptosis through modulation of cardiolipin oxidation in hepatocellular carcinoma: A novel link between 
oxidative stress and cancer. Free Radic Biol Med. 2017;102:67-76. http://dx.doi.org/10.1016/j. freeradbiomed.2016.10.494

83. Lu Y, Li N, Gao L, Xu YJ, Huang C, Yu K, et al. Acetylcarnitine Is a Candidate Diagnostic and Prognostic Biomarker of Hepatocellular Carcinoma. Cancer Res. 2016;76(10):2912-20. http://dx.doi. org/10.1158/0008-5472.CAN-15-3199

84. Saito K, Ikeda M, Kojima Y, Hosoi H, Saito Y, Kondo S. Lipid profiling of pre-treatment plasma reveals biomarker candidates associated with response rates and hand-foot skin reactions in sorafenibtreated patients. Cancer Chemother Pharmacol. 2018;82(4):677-84. http://dx.doi.org/10.1007/ s00280-018-3655-z

85. Chen S, Yin P, Zhao X, Xing W, Hu C, Zhou L, et al. Serum lipid profiling of patients with chronic hepatitis B, cirrhosis, and hepatocellular carcinoma by ultra fast LC/IT-TOF MS. Electrophoresis. 2013;34(19):2848-56. http://dx.doi.org/10.1002/elps.201200629

86. Lin L, Ding Y, Wang Y, Wang Z, Yin X, Yan G, et al. Functional lipidomics: Palmitic acid impairs hepatocellular carcinoma development by modulating membrane fluidity and glucose metabolism. Hepatology. 2017;66(2):432-48. http://dx.doi.org/10.1002/hep.29033

87. Perry RH, Bellovin DI, Shroff EH, Ismail AI, Zabuawala T, Felsher DW, et al. Characterization of MYCinduced tumorigenesis by in situ lipid profiling. Anal Chem. 2013;85(9):4259-62. http://dx.doi. org/10.1021/ac400479j

88. Birjandi AP, Bojko B, Ning Z, Figeys D, Pawliszyn J. High throughput solid phase microextraction: A new alternative for analysis of cellular lipidome? J Chromatogr B Analyt Technol Biomed Life Sci. 2017;1043:12-19. http://dx.doi.org/10.1016/j.jchromb.2016.09.034

89. Li Z, Guan M, Lin Y, Cui X, Zhang Y, Zhao Z, et al. Aberrant lipid metabolism in hepatocellular carcinoma revealed by liver lipidomics. Int J Mol Sci. 2017;18(12):E2550:1-15. http://dx.doi.org/10.3390/ ijms18122550

90. Puri P, Wiest MM, Cheung O, Mirshahi F, Sargeant C, Min HK, et al. The plasma lipidomic signature of nonalcoholic steatohepatitis. Hepatology. 2009;50(6):1827-38. http://dx.doi.org/10.1002/ hep. 23229

91. Patterson AD, Maurhofer O, Beyoglu D, Lanz C, Krausz KW, Pabst T, et al. Aberrant lipid metabolism in hepatocellular carcinoma revealed by plasma metabolomics and lipid profiling. Cancer Res. 2011;71(21):6590-600. http://dx.doi.org/10.1158/0008-5472.CAN-11-0885

92. Kihara A. Very long-chain fatty acids: Elongation, physiology and related disorders. J Biochem. 2012;152(5):387-95. http://dx.doi.org/10.1093/jb/mvs105

93. Fages A, Duarte-Salles T, Stepien M, Ferrari P, Fedirko V, Pontoizeau C, et al. Metabolomic profiles of hepatocellular carcinoma in a European prospective cohort. BMC Med. 2015;13:242. http://dx.doi. org/10.1186/s12916-015-0462-9

94. Zeng J, Yin P, Tan Y, Dong L, Hu C, Huang Q, et al. Metabolomics study of hepatocellular carcinoma: Discovery and validation of serum potential biomarkers by using capillary electrophoresis-mass spectrometry. J Proteome Res. 2014;13(7):3420-31. http://dx.doi.org/10.1021/pr500390y

95. Cheng C, Geng F, Cheng X, Guo D. Lipid metabolism reprogramming and its potential targets in cancer. Cancer Commun (Lond). 2018;38(1):27. http://dx.doi.org/10.1186/s40880-018-0301-4

96. Liu Q, Luo Q, Halim A, Song G. Targeting lipid metabolism of cancer cells: A promising therapeutic strategy for cancer. Cancer Lett. 2017;401:39-45. http://dx.doi.org/10.1016/j.canlet. 2017.05 .002

97. Li N, Zhou ZS, Shen Y, Xu J, Miao HH, Xiong Y, et al. Inhibition of the sterol regulatory elementbinding protein pathway suppresses hepatocellular carcinoma by repressing inflammation in mice. Hepatology (Baltimore, Md). 2017;65(6):1936-47. http://dx.doi.org/10.1002/hep.29018

98. Gingold JA, Zhu D, Lee DF, Kaseb A, Chen J. Genomic profiling and metabolic homeostasis in primary liver cancers. Trends Mol Med. 2018;24(4):395-411. http://dx.doi.org/10.1016/j. molmed.2018.02.006

99. Loomba R, Kayali Z, Noureddin M, Ruane P, Lawitz EJ, Bennett M, et al. GS-0976 reduces hepatic steatosis and fibrosis markers in patients with nonalcoholic fatty liver disease. Gastroenterology. 2018;155(5):1463-73 e6. http://dx.doi.org/10.1053/j.gastro.2018.07.027 
100. Mansourian PG, Yoneda M, Krishna Rao M, Martinez FJ, Thomas E, Schiff ER. Effects of statins on the risk of hepatocellular carcinoma. Gastroenterol Hepatol (N Y). 2014;10(7):417-26.

101. Jin H, He Y, Zhao P, Hu Y, Tao J, Chen J, et al. Targeting lipid metabolism to overcome EMT-associated drug resistance via integrin beta3/FAK pathway and tumor-associated macrophage repolarization using legumain-activatable delivery. Theranostics. 2019;9(1):265-78. http://dx.doi.org/10.7150/ thno. 27246

102. Wong A, Chen S, Yang LK, Kanagasundaram Y, Crasta K. Lipid accumulation facilitates mitotic slippage-induced adaptation to anti-mitotic drug treatment. Cell Death Discov. 2018;4:109. http://dx.doi. org/10.1038/s41420-018-0127-5

103. Luo J, Hong Y, Lu Y, Qiu S, Chaganty BK, Zhang L, et al. Acetyl-CoA carboxylase rewires cancer metabolism to allow cancer cells to survive inhibition of the Warburg effect by cetuximab. Cancer Lett. 2017;384:39-49. http://dx.doi.org/10.1016/j.canlet.2016.09.020

104. Fekry B, Jeffries KA, Esmaeilniakooshkghazi A, Ogretmen B, Krupenko SA, Krupenko NI. CerS6 is a novel transcriptional target of p53 protein activated by non-genotoxic stress. J Biol Chem. 2016;291(32):16586-96. http://dx.doi.org/10.1074/jbc.M116.716902

105. Jones SF, Infante JR. Molecular pathways: Fatty acid synthase. Clin Cancer Res. 2015;21(24):5434-8. http://dx.doi.org/10.1158/1078-0432.CCR-15-0126

106. Degagne E, Pandurangan A, Bandhuvula P, Kumar A, Eltanawy A, Zhang M, et al. Sphingosine-1phosphate lyase downregulation promotes colon carcinogenesis through STAT3-activated microRNAs. J Clin Invest. 2014;124(12):5368-84. http://dx.doi.org/10.1172/JCI74188

107. Chen HW, Chang YF, Chuang HY, Tai WT, Hwang JJ. Targeted therapy with fatty acid synthase inhibitors in a human prostate carcinoma LNCaP/tk-luc-bearing animal model. Prostate Cancer Prostatic Dis. 2012;15(3):260-4. http://dx.doi.org/10.1038/pcan.2012.15

108. Koul D, Shen R, Kim YW, Kondo Y, Lu Y, Bankson J, et al. Cellular and in vivo activity of a novel PI3K inhibitor, PX-866, against human glioblastoma. Neuro Oncol. 2010;12(6):559-69. http://dx.doi. org/10.1093/neuonc/nop058

109. Antoon JW, Liu J, Ponnapakkam AP, Gestaut MM, Foroozesh M, Beckman BS. Novel D: -erythro N-octanoyl sphingosine analogs as chemo- and endocrine-resistant breast cancer therapeutics. Cancer Chemother Pharmacol. 2010;65(6):1191-5. http://dx.doi.org/10.1007/s00280-009-1233-0

110. Mahdy AE, Cheng JC, Li J, Elojeimy S, Meacham WD, Turner LS, et al. Acid ceramidase upregulation in prostate cancer cells confers resistance to radiation: AC inhibition, a potential radiosensitizer. Mol Ther. 2009;17(3):430-8. http://dx.doi.org/10.1038/mt.2008.281

111. Shin SW, Seo CY, Han H, Han JY, Jeong JS, Kwak JY, et al. 15d-PGJ2 induces apoptosis by reactive oxygen species-mediated inactivation of Akt in leukemia and colorectal cancer cells and shows in vivo antitumor activity. Clin Cancer Res. 2009;15(17):5414-25. http://dx.doi.org/10.1158/1078-0432. CCR-08-3101 